\title{
A influência da marca nos postos de abastecimento de combustíveis
}

\section{The Influence of Brand in Gas Stations}

\section{Artigo \\ Original}

\section{Original \\ Paper}

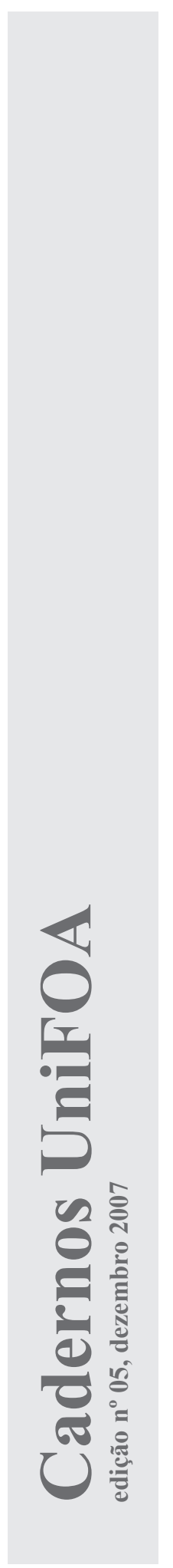

\author{
Maria Aparecida Nasr ${ }^{1}$ \\ Zilda Maria Contesini dos Santos ${ }^{2}$
}

Palavras-chaves:
Combustíveis
Postos com
Bandeira
Qualidade
Preço

\begin{abstract}
The aim of this work is to analyze the decisive process of consumers in relation to new criteria for choosing quality and price of gas in gas stations. The flexibility provided by the deregulation made it possible for the gas stations to keep joined to the distributors that gave them the brand or not. The ones that decided to unjoin the distributors encouraged the appearance of a new class of offerers called no brand. The survey was done with consumers in gas stations with or without brands in Volta Redonda County in Rio de Janeiro. In order to test if consumers' attitudes towards both gas station classes have presented distinct behavior, the variance analysis methodology was adopted. Results have shown that those who choose gas stations that have traditional distributors look for superior quality of the product whereas those who choose gas stations without a brand prefer low prices.
\end{abstract}

Key words:

Gases

Gas stations with Brands

Quality

Price

\section{Introdução}

As modificações introduzidas pela nova lei do petróleo - Lei no. 9478 - que foi promulgada em janeiro de 1997 objetivava definir as diretrizes da abertura da indústria de combustíveis a novos investimentos em todas as fases da cadeia de petróleo. Finalmente efetivada em 2002, a lei em questão trouxe um novo impulso ao mercado de combustível que

de estagnado passou para um cenário de forte concorrência e de livre mercado. Com essa flexibilização no mercado de combustível, os postos tiveram a opção de permanecer no negócio sem vínculo contratual de exclusividade com as distribuidoras que lhes deram a bandeira. A grande maioria preferiu vincular-se a uma distribuidora, apesar do

${ }^{1}$ Mestranda - Administração - UniFOA

${ }^{2}$ Mestre - Administração - UniFOA 
crescimento da bandeira branca.

Os postos de bandeiras são aqueles que exibem marca comercial de uma distribuidora de combustível, e por força de contrato, comercializam apenas combustíveis (gasolina) fornecidos pelo distribuidor, detentores das marcas comerciais exibidas. Estes postos podem pertencer às próprias distribuidoras, sob forma de operação terceirizada, já as distribuidoras não podem operar, diretamente, postos de revenda, ou serem franqueados a proprietários individuais. Os demais postos que não exibem a marca comercial do distribuidor, conhecido como postos de bandeira branca, não se apresentam com vínculo a nenhuma distribuidora, podendo adquirir combustíveis de qualquer empresa autorizada pela ANP.

As compras são concretizadas com o fornecedor que oferecer as melhores condições comerciais, ou seja, melhor preço, ou forma de pagamento. Como exigência da agência reguladora, esses postos devem identificar em cada bomba abastecedora a respectiva origem do combustível, isto é, o distribuidor responsável pelo fornecimento. Por outro lado, representar a marca comercial de uma distribuidora pode ser muito lucrativo para os postos. As grandes distribuidoras dedicam muitos recursos em propaganda e marketing. Um posto que possua bandeira de uma empresa que investe em propaganda, tira proveitos desse investimento. Em última análise, um posto filiado a uma grande distribuidora se torna parte da estratégia de competição no disputado mercado de distribuição de combustíveis. Na marca comercial da respectiva distribuidora está a representação de um diferencial para o mesmo posto.

O consumidor, ao abastecer seu veículo, muitas vezes, associa este serviço à bandeira que o posto representa. Desta maneira, as bandeiras passaram a constituir uma barreira à entrada no mercado de distribuição dos chamados postos de bandeira branca ou sem bandeira, pois as pequenas distribuidoras, que não possuem capitais suficientes, não conseguem atingir o mesmo nível de competição das marcas estabelecidas. Esse novo contexto apresentado em um mercado desregulamentado, com apertadas margens de lucratividade, conseqüência da alta competitividade, motivou, entre alguns postos, a adoção de práticas irregulares quanto ao trato dos combustíveis, colocando em risco a qualidade dos produtos distribuídos.

Neste cenário, passou a existir a necessidade de reavaliação no processo de decisão do consumidor que, desta maneira, precisava escolher entre os diferentes postos, tendo por parâmetros de escolha o preço baixo e a qualidade superior do combustível.

\section{Rerefencial Teórico}

\subsection{Postos com e sem Bandeira.}

Previsto no artigo 11 da Portaria no. 61 em Março de 1995, do Ministério das Minas e Energia, o revendedor de combustível está isento da obrigatoriedade de filiação à marca do distribuidor que lhe fornece o combustível. Marcada pela abertura do setor e quebra do monopólio, surgem os postos de bandeira branca. Estes, segundo a Agencia Nacional do Petróleo (ANP), "são os postos que não estão vinculados a uma determinada distribuidora e podem comprar e vender combustíveis de distribuidoras diferentes, sem necessidade de ostentar sua marca. Por outro lado, os postos com bandeira estão vinculados a uma determinada distribuidora e podem apenas comprar e vender combustível daquela distribuidora, ostentando sua marca" (ANP, portaria no. 116/00). Até o final de 2005, na tabela 1 , segundo dados publicados pela ANP existiam 35.585 postos revendedores de combustíveis automotivos (Tabela 1), sendo $47,7 \%$ das cinco maiores distribuidoras (BR,Ipiranga, Shell, Chevron e Esso), dos demais $4.699(13,2 \%)$ exibem bandeira de outras 126 distribuidoras e 13.897 (39,1\%) são postos de bandeira branca.

\subsection{Atributos Tangível e Intangível}

Elementos intrínsecos do produto incluem os componentes físicos $\mathrm{e}$ as características funcionais, tais como design, cor, resistência, sabor e matérias-primas. Os extrínsecos associam-se ao produto, mas não fazem parte da sua composição física, dos quais são exemplos o preço, a propaganda, a marca e a disposição no ponto de venda. São freqüentes as situações em que o consumidor tem que escolher entre marcas de produtos muitos similares em termos de atributos intrínsecos, tendo que recorrer a atributos 
extrínsecos. Aaker, (1991) afirma que a marca exerce efeito acentuado nas decisões de compra do consumidor. Porém, a imagem que o consumidor tem de uma marca é definida através do conjunto de associações e atributos que ele reconhece e conecta ao nome dessa marca. A marca passa a significar não apenas um produto ou serviço, mas um conjunto de valores e atributos tangíveis e intangíveis para o consumidor, que precisa diferenciar a marca daquelas que lhe são similares (PINHO 1996, p.43).

Tabela 01 - Postos revendedores segundo Regiões - 2005

\begin{tabular}{|l|c|c|c|c|c|c|c|c|}
\hline \multicolumn{7}{|c|}{ Quantidade de postos revendedores de combustíveis automotivos } \\
\hline $\begin{array}{l}\text { Região/ } \\
\text { Federação }\end{array}$ & Total & BR & Ipiranga & Shell & Chevron & Esso & $\begin{array}{c}\text { Bandeira } \\
\text { Branca }\end{array}$ & Outras* \\
\hline Brasil & 35585 & $\begin{array}{c}6756 \\
(18,9 \%)\end{array}$ & $\begin{array}{c}4138 \\
(11,6 \%)\end{array}$ & $\begin{array}{c}1890 \\
(5.3 \%)\end{array}$ & $\begin{array}{c}2352 \\
(6,6 \%)\end{array}$ & $\begin{array}{c}1853 \\
(5,2 \%)\end{array}$ & $\begin{array}{c}13897 \\
(39,1 \%)\end{array}$ & $\begin{array}{c}4699 \\
(13,2 \%)\end{array}$ \\
\hline Norte & 2047 & 393 & 98 & 3 & 160 & 19 & 990 & 384 \\
\hline Nordeste & 6963 & 1407 & 353 & 249 & 421 & 273 & 2685 & 1575 \\
\hline Sudeste & 1599 & 2983 & 1577 & 1025 & 896 & 1030 & 7058 & 1250 \\
\hline Sul & 7352 & 1291 & 1725 & 360 & 651 & 467 & 1631 & 1227 \\
\hline Centro-Oeste & 3224 & 682 & 385 & 73 & 224 & 64 & 1533 & 263 \\
\hline
\end{tabular}

Fonte: ANP/SAB (*) Inclui outras 126 bandeiras

Dependendo da categoria do produto, o consumidor poderá privilegiar uma ou outra classe de atributos. Para Zeithaml (1988) duas proposições auxiliam a estruturar esta análise. Primeira, quando os atributos intrínsecos prevalecem nas avaliações do consumidor: a) durante o consumo do produto; b) nos estágios que antecedem a compra, quando os atributos intrínsecos caracterizam-se mais como elementos de procura do que como atributos experienciais (avaliadas durante o consumo); c) quando os atributos extrínsecos possuem elevado valor preditivo para o consumidor acerca do valor do produto. Numa segunda etapa, quando os atributos extrínsecos prevalecem: a) nas situações da primeira compra; os atributos intrínsecos do produto não estão disponíveis; b) quando o consumidor conclui que o esforço e o tempo exigidos para avaliar os atributos intrínsecos não são compensadores; c) quando o consumidor mostra-se incapaz de avaliar os atributos intrínsecos. Portanto, o consumidor seleciona, integra e avalia informações relacionadas às marcas de produtos para chegar a um julgamento e enfim decidir sua escolha. O processo de decisão de compra está baseado nas análises que o consumidor faz desses atributos, levando-o a formar percepções sobre os níveis de qualidade, preço e valor das diferentes alternativas consideradas para compra (ZEITHAML, 1988).

\subsection{Qualidade percebida}

Zeithaml (1988, p.86), identifica qualidade como uma característica de superioridade ou excelência, ou seja, "a qualidadepercebida corresponde aojulgamento do consumidor sobre a superioridade genérica de um produto". Gale (1996) conceitua qualidade percebida pelo mercado como sendo a opinião dos clientes sobre os produtos ou serviços, comparativamente com os da concorrência, enquanto o valor percebido é a qualidade percebida pelo mercadoajustada pelo preço relativo do produto ou serviço. $\mathrm{O}$ mesmo autor defende que a análise do valor do cliente dividi-se em duas partes, sendo: o perfil da qualidade percebida pelo mercado corresponde aos benefícios para o cliente e o perfil do preço percebido pelo mercado corresponde aos sacrifícios do cliente, relativamente à concorrência. A qualidade deve ser vista como o potencial intrínseco aos atributos do produto ou serviço de prover satisfação, enfatizando que a qualidade percebida é, então, dependente da função de utilidade para o cliente em relação ao nível de qualidade ou desempenho fornecido (ANDERSON et al, 1994). Já, a satisfação é um construto que depende da função valor, que pode ser definida como o quociente entre a qualidade percebida e o preço, ou como a relação entre os benefícios recebidos pelo cliente comparativamente aos custos ou sacrifícios incorridos para sua obtenção (ANDERSON, et al, 1994). Pode- 
se entender a qualidade como a percepção atual do cliente sobre o desempenho de um produto ou serviço e a satisfação como sendo baseada não somente na experiência atual, mas também em experiências passadas e em experiências futuras, antecipadas pelo julgamento do cliente em virtude de suas experiências acumuladas, além da projeção de suas expectativas (FORNELL, 1995).

\subsection{Preço Percebido}

Douglas (1991, p. 436) argumenta que o comprador só efetuará a compra se perceber que o preço de determinado produto é maior que o preço pedido pelo fornecedor, o mesmo ocorrendo para os atributos e ou serviços complementares oferecidos. O que o autor denomina de preço percebido pelo comprador seria "a avaliação e a valoração que se faz mentalmente sobre o bem e o serviço oferecido, o grande problema é que dificilmente esse valor é revelado para o fornecedor". Para Sheth et al (2001, p.294), "os clientes muitas vezes utilizam o preço como uma pista de qualidade, ou seja, como uma base para inferência sobre a qualidade do produto o serviço". Para Grönroos, (1996) e Monroe (1991), valor percebido pelo cliente é a razão entre benefícios percebidos e sacrifícios percebidos, quando sacrifícios percebidos incluem todos os custos do comprador ao fazer uma compra, tais como preço de compra, custos de aquisição, transporte, instalação, manuseio, reparos e manutenção, riscos de falha ou de desempenho ruim.

Os benefícios percebidos são combinações dos atributos físicos, de serviço e suporte técnico disponível em relação a algum uso particular do produto, assim como o preço de compra e outros indicadores de qualidade percebida. Monroe (1991) está ressaltando, quando coloca o preço de compra tanto como sacrifício quanto como benefício, os aspectos da percepção do cliente bastante pessoais, como necessidade de status (se um preço elevado puder significar um benefício, por exemplo), ou de se sentir fazendo um "bom negócio" (se um preço baixo, com qualidade percebida similar a concorrência, puder significar estar fazendo economia sem abrir mão de outros aspectos). Anderson e Narus (1999, p.6) não definem valor do ponto de vista do cliente. Para os autores a definição de valor não tem nenhuma perspectiva particularmente especificada, sendo antes de tudo um construto, quando se pode apenas estimar valor. Os mesmos trabalham com a noção de valor como um conceito a ser negociado entre as partes mais do que a visão do cliente sobre o produto da empresa fornecedora. Segundo eles, mudanças no valor podem ocorrer de duas maneiras: uma a variação de custo para o cliente sem mudanças no desempenho do produto, e outra a variação no desempenho, com os custos para o cliente permanecendo constantes. Resumidamente, pode se considerar como benefício tudo o que é recebido pelo cliente em troca do que é dado para a obtenção do produto, variando de acordo com a percepção de cada cliente em um determinado momento.

Analogamente, sacrifícios englobam tudo que é dado pelo cliente em troca do que é recebido, sendo que o que é dado também varia de acordo com consumidores. Todos os custos incorridos no processo de troca, além do preço individual, estão inclusos nos sacrifícios do consumidor para obtenção do produto. Devese ressaltar, novamente, que preço pode ser visto como benefício em algumas situações específicas, sendo um sacrifício na maioria das situações.

Quando da elaboração da política de preços também devemos levar em consideração alguns aspectos relativos ao comportamento do mercado consumidor, como a elasticidade que reflete a sensibilidade dos clientes às alterações de preço, e o estudo dos segmentos de mercado o qual permite o conhecimento das principais características dos consumidores, como, por exemplo, se são orientados para o custo ou benefício. Também, o risco percebido como um componente do preço percebido é parte integrante da percepção de valor global do consumidor, é apresentado como um parâmetro motivacional atuante no processo de decisão de compra do consumidor.

A avaliação e o julgamento sobre o produto decorrem da informação disponível no ambiente de decisão de compra e, principalmente, do conhecimento armazenado na memória do consumidor. Quanto maior o conhecimento do consumidor sobre o produto, contando inclusive com experiências de utilização ou de consumo, mais simples e mais rapidamente será desenvolvido o processo decisório de compra. A avaliação 
e o julgamento sobre o produto decorrem da informação disponível no ambiente de decisão de compra e, principalmente, do conhecimento armazenado na memória do consumidor. Quanto maior o conhecimento do consumidor sobre o produto, contando inclusive com experiências de utilização ou de consumo, mais simples e mais rapidamente será desenvolvido o processo decisório de compra.

O processo decisório do consumidor tem uma natureza deliberada, o próprio raciocínio lógico. O caminho decisório analítico justifica a utilização de critérios de compra funcionais ou utilitários por parte do consumidor em relação ao produto (MOWEN, 1988). Quando o consumidor depara-se com uma inovação busca uma grande quantidade de informação para compreender o significado global do produto. Assim, pode formar os critérios de decisão de compra.

\section{Hipóteses}

Segundo Sheth, Mittal e Newman (2001), o processo decisório do consumidor passa por cinco estágios: reconhecimento do problema, busca de informação, avaliação de alternativas, compra e experiência póscompra. Atributos relevantes determinam a tendência do consumidor para uma ou outra alternativa. A presente pesquisa se propõe a avaliar os pressupostos propostos no modelo de Zeithaml (1988).

Namedida em que os preços atribuídos ao produto são percebidos pelo consumidor como acima da média, ocorre a possibilidade de que os consumidores julguem o produto como detentor de qualidade equivalente, ou seja, maior o preço maior o sentimento de qualidade superior. Tal situação deve motivar os clientes de optarem por abastecer em postos com bandeira. Autores como Gronroos (1993), Hamel e Prahalad (1995), Sveiley (1998) e Gravin (2002), estabeleceram a reputação como um dos fatores que contribuem para imagem da organização para a confiança e a percepção da qualidade. Sendo esses fatores importantes para a credibilidade, no que resulta no fato de consumidores que são avessos aos riscos, busque o abastecimento em postos que possuem, imagem e reputação, dando preferência aos postos com bandeira, estabelecendo a seguinte hipótese.
H1: consumidores que preferem produtos com qualidade superior tendem a optar por abastecer seus automóveis em postos com bandeira.

Zeithaml (1998), diz que a decisão de escolha do consumidor é influenciada pelas percepções de qualidade, valor e preço. Ocorre um intercâmbio de algo que representa valor e preço para o consumidor e tal transação dependerá amplamente da percepção que o cliente tem quanto ao nível de benefícios que estará recebendo por seus sacrifícios (MAHFOOD, 1994). A palavra preço é muitas vezes associada à percepção de escolha de postos sem bandeira. A influência do preço como atributo resulta que consumidores que não são avessos aos riscos e a qualidade do combustível; optem em abastecer em postos sem bandeira; estabelecendo a seguinte hipótese $\mathrm{H} 2$ :

$\mathrm{H} 2 \mathrm{O}$ valor percebido (preço) é afetado nos consumidores em optar por abastecer seus automóveis em postos sem bandeira.

\section{Metodologia}

A pesquisa adotada para o desenvolvimento deste trabalho utiliza uma abordagem causal, quando, por meio de experimentação, os sujeitos da pesquisa são solicitados a manifestar suas preferências vinculadas a duas variáveis independentes (MAlHOTRA, p.214-217). Para a coleta dos dados, o método utilizado foi de pesquisa tipo survey por meio de entrevista pessoal com abordagem direta em ambiente nãocontrolado. A pesquisa survey pode ser definida como a obtenção de dados ou informações sobre características, ações ou opiniões de um determinado grupo de pessoas, indicado como representante de uma população alvo, por meio de um instrumento, normalmente, o questionário (PINSONNEAULT e KRAEMER, 1993, p.56).

O procedimento de amostragem foi aleatório do tipo sistemático, as observações foram coletadas a partir de abordagens a clientes em cinco postos de abastecimento localizados na cidade de Volta Redonda-RJ, nos dias úteis compreendidos entre 04 a 08 de junho em horário comercial. Ao final da coleta, foram realizadas 50 entrevistas válidas, 
25 para postos com e 25 para postos sem bandeira. Foram coletados dados primários a partir de um questionário estruturado com oito perguntas, sendo duas com respostas em escala Likert de cinco pontos e as demais quatro questões com escala nominal, relacionada aos dados de gênero, idade, formação e utilização do veículo.

A análise estatística utilizada foi de análise de variância a dois fatores sem interação, a qual visa, fundamentalmente, verificar se existe diferença significativa entre as médias e se os fatores exercem influência na variável resposta da presente pesquisa. Segundo Hair (2005, p.272), a “análise de variância é a técnica estatística utilizada para determinar se as amostras de dois ou mais grupos surgem de populações com médias iguais". Para tratamento dos dados utilizado o software SPSS versão 13.0.

\section{Análise dos Reseultados}

A distribuição de gênero apresenta $50 \%$ de entrevistados homens e 50\% mulheres para postos com bandeira, adotado também o mesmo percentual para postos sem bandeira $50 \%$ masculinos e $50 \%$ femininos.

Em relação à idade dos entrevistados nos postos com bandeira, a distribuição dos resultados é de $30 \%$ dos 19 a 29 anos, 28\% dos 30 a 39 anos. $32 \%$ dos 40 a 49 anos e $6 \%$ dos 50 a 59 anos. Nos postos sem bandeira, os resultados foram de $54 \%$ entre os 18 a 29 anos, 24\% dos 30 a 39 anos; $20 \%$ dos 40 a 49 anos e 50 a 59 anos.

O grau de instrução dos entrevistados nos postos com bandeira apresentou no ensino médio incompleto $16 \%$; ensino médio completo e superior incompleto $52 \%$ e superior completo $32 \%$, nos postos sem bandeira encontrou-se ensino médio incompleto $24 \%$, ensino médio completo e superior incompleto $36 \%$ e superior completo $40 \%$.

Quanto ao critério de como utilizar o veículo verificou-se que nos postos com bandeira $76 \%$ utilizam o veículo para lazer, passeio e $24 \%$ para fins comerciais, no entanto; nos postos sem bandeira $60 \%$ utilizam o veículo para lazer e $40 \%$ para fins comerciais.

Os cinco locais de entrevista, três postos com bandeira e dois postos sem bandeira, possuem como requisito o preço médio da gasolina; sendo que os postos sem bandeira possuem uma diferença de preço.

Após a revisão da literatura estabeleceu-se inicialmente um conjunto de respostas adquiridas dos resultados de pesquisa; estabelecendo-se dois construtos explicativos do critério de decisão do consumidor.

Tabela 2 - Estatística Descritivas das Variáveis Qualidade e Preço

Descrição dos Resultados

\begin{tabular}{|cc|c|c|c|c|c|c|c|c|}
\hline & & N & Média & Dispersão & Erro & \multicolumn{2}{|c|}{$\begin{array}{c}\text { 95\% Intervalo de } \\
\text { confiança p/Média }\end{array}$} & Min. & Max. \\
\hline \multirow{2}{*}{ Variável 01 } &, 00 & 25 & 1,800 &, 7071 &, 1414 & 1,508 & 2,091 & 1,0 & 3,0 \\
Qualidade & 1,0 & 25 & 3,040 &, 9345 &, 1869 & 2,654 & 3,425 & 2,0 & 5,0 \\
& Tot & 50 & 2,420 & 1,0319 &, 1459 & 2,126 & 2,713 & 1,0 & 5,0 \\
\hline \multirow{2}{*}{ Variável 02 } &, 00 & 25 & 3,120 & 1,1661 &, 2332 & 2,638 & 3,601 & 1,0 & 5,0 \\
Preço & 1,0 & 25 & 1,880 & 1,0132 &, 2026 & 1,461 & 2,298 & 1,0 & 4,0 \\
& Tot & 50 & 2,500 & 1,2494 &, 1767 & 2,144 & 2,855 & 1,0 & 4,0 \\
\hline
\end{tabular}

Tabela 3 - Analise de Variância para as Variáveis Qualidade e Preço

ANOVA

\begin{tabular}{|cc|c|c|c|c|c|}
\hline & & $\begin{array}{c}\text { Soma dos } \\
\text { Quadrados }\end{array}$ & df & $\begin{array}{c}\text { Média dos } \\
\text { Quadrados }\end{array}$ & F & Sig. \\
\hline \multirow{2}{*}{ Variável 02 } & Entre grupos & 19,200 & 1 & 19,220 & 27,990 &, 000 \\
& Com grupos & 32,960 & 48 &, 687 & & \\
\hline \multirow{4}{*}{ Variável 03 } & Total & 52,180 & 49 & & & \\
& Entre grupos & 19,220 & 1 & 19,220 & 16,106 &, 000 \\
& Com grupos & 57,280 & 48 & 1,193 & & \\
\hline
\end{tabular}


Os resultados, após os cálculos estatísticos pelo SPSS, resultaram nas tabelas 2 e 3. A primeira traz que a dispersão da qualidade em relação ao posto sem bandeira $(0,93452)$ é maior do que no posto com bandeira $(0,70711)$. O preço, outro atributo relacionado na tabela 2, apresenta uma dispersão em relação à média nos postos sem bandeira $(1,01325)$ e nos postos com bandeira de $(1,16619)$. Os resultados da análise de dispersão (estatística descritiva) indicam uma futura tendência de que os postos com bandeira influenciam na escolha dos consumidores.

Para a validação discriminante dos resultados a tabela 3 , demonstra a análise de variância que é uma técnica para determinar se as médias de dias ou mais populações, (grupos - postos com bandeira, postos sem bandeira), são iguais. A lógica de um teste ANOVA referese no presente estudo à situação em que duas estimativas independentes de variância para a variável dependente são comparadas, uma que reflete a variabilidade geral de respondentes dentro dos grupos e outra que representa as diferenças entre grupos atribuíveis aos efeitos de tratamento.

A variância dentro dos grupos (quadrado médio dentro dos grupos) é uma estimativa da variabilidade média sobre a variável dependente dentro de um grupo e é baseada em desvios a partir de suas respectivas médias de grupos, representando a variabilidade dentro dos grupos. A estimativa de variância entre grupos (quadrado médio entre grupos) testa a variabilidade das médias de grupos sobre a variável dependente e baseia-se em desvios de médias de grupos a partir da média geral.

Para a análise da ANOVA, é necessário determinar se a estatística $\mathrm{F}$, permite a avaliação das hipóteses em análise. Se a análise tem diversos tratamentos diferentes (variáveis independentes são grupos postos com bandeira e postos sem bandeira), então estimativas são calculadas para cada tratamento, bem como estimativas de F. Primeiro, determina-se o valor crítico de F crítico, usando a distribuição com graus de liberdade para um nível especificado (K-1); onde $\mathrm{K}$ é o número de grupos (postos com bandeira e postos sem bandeira). Se o valor da estatística F calculada pela ANOVA exceder a F crítica, conclui-se que as médias nos grupos não são todas iguais, portanto, se aceita a hipótese de desigualdade significativa entre médias.

Para a verificação dos parâmetros dos atributos, a literatura indica que para ser significativo, o valor de $\mathrm{F}$ tem que ser maior que 3,354; Para o caso da H1, tem-se que a qualidade percebida determina a preferência do consumidor por abastecer em postos com bandeira, nesse caso, o valor do teste $\mathrm{F}$ da razão de variância entre os dois grupos (com bandeira / sem bandeira) é igual a 27,990; portanto, superior ao limite mínimo especificado, o que nos leva a aceitar a hipótese $\mathrm{H} 1$; de que a qualidade é um fator determinante na opção do consumidor por abastecer em postos com origem certificada, também denominados postos com bandeira.

Quanto ao atributo preço praticado o valor do F é 16,106; portanto superior ao limite mínimo especificado, o que nos leva a aceitar a hipótese $\mathrm{H} 2$; de que a qualidade é um fator determinante na opção do consumidor por abastecer em postos com origem não certificada, também denominados postos sem bandeira.

A ANOVA indica que é verdade que existe uma diferença significativa entre os dois grupos, tendo em análise que o preço também influência na escolha dos postos de gasolina, verifica-se que a análise de variância que estuda o procedimento entre grupos, constata que ocorre uma notável diferença entre postos com bandeira e sem bandeira. Comprova que a qualidade influência na escolha de consumidor. Por outro lado, o preço também é um indicador influente. $\mathrm{O}$ fato da qualidade evidenciar-se na opção de escolha do posto, faz com que o valor percebido (preço) deixe de apresentar a real significância.

\section{Conclusão}

A pesquisa para identificar atitudes de motivação de compra de combustíveis em postos com e sem bandeira reflete algumas constatações importantes. Apesar das limitações inerentes à população pesquisada, específica ao município de Volta Redonda, os resultados obtidos refletem na prática um comportamento esperado.

Os consumidores que procuram por qualidade do combustível estão dispostos a pagar um preço relativamente mais elevado ou 
premium quandocomparadoàqueles praticados pelos postos sem bandeira. Isto porque aqueles postos que possuem distribuidor conhecido transferem ao consumidor os benefícios da segurança da marca, bem como a sensibilização decorrente do composto promocional. Por decorrência, os consumidores tendem a tentar reduzir seu nível de risco e nível de ansiedade conferindo maior grau de credibilidade aos combustíveis ofertados por tais postos.

Analogamente, os postos sem bandeira não ostentam os benefícios da marca e, assim, não recebem com a mesma intensidade a percepção de segurança manifestada pelo consumidor. Deste modo, este busca uma compensação pelo risco percebido enfrentado através do menor sacrifício monetário.

Recomenda-se, para estudos futuros, que sejam realizadas pesquisas em segmentos específicos de consumidores, a exemplo da natureza do uso, separando aqueles que utilizam o veículo como fonte de renda como os táxis, daqueles que o utilizam meramente para deslocamento e lazer. Outra base de segmentação que deve trazer resultados interessantes é a renda, neste caso espera-se que preços premium encontrem apelo apenas entre as camadas mais afluentes, resultando os consumidores de menor renda entre aqueles que buscam preço baixo em detrimento da qualidade.

\section{Referências}

ANDERSON, J.C.; NARUS, J.A. Business Market Management: Understanding, Creating and Delivering Value, Prentice-Hall, Inc.: USA, 1999.

ANDERSON, E. W.; FORNELL, C.; RUST, R. T. Customer Satisfaction, productivity, and profitability: differences between goods and services. Marketing Science. v. 16, n. 2, p. 129-45, 1997.
ANDERSON,E.W.; FORNELL, C.;LEHMANN, D.R. Perceived quality, customer satisfaction, market share, and profitability. Working Paper, NQRC (National Quality Research Center): The University of Michigan, 1992.

CHANG, T.Z.; WILDT, A.R. Price, Product Information, and Purchase Intention: An Empirical Study. Journal of the Academy of Marketing Science. v.22, n.1, winter 1994, p.16-27

FORNELL, C. Productivity, quality, and customer satisfaction as strategic success indicators at firm and national level. Advances in Strategic Management. v. 11A, p. 217-29, 1995.

GALE, B.T. Gerenciando o valor do cliente: criando qualidade e serviços que os clientes podem ver. São Paulo: Pioneira, 1996.

GRONROOS, Christian, Marketing: Gerenciamento e Serviços, Rio de Janeiro:Elsevier, 2003.

MALHOTRA, Naresh K. Pesquisa de Marketing: Uma Orientação Aplicada. 4a ed, Porto Alegre: Artmed, 2006.

MOWEN, John C., MINOR, Michael S. Comportamento do Consumidor. São Paulo: Prentice Hall, 1988.

PINHO, J. B. O poder das marcas. São Paulo: Summus, 1996.

SHETH, J. N., MITTAL, B., NEWMAN, B.I. Comportamento do cliente. São Paulo: Atlas,2001.

WOODRUFF, Robert, Customer Value: the next source advantage. Journal of the Academy of Marketing Science. Greenvale, 1997, v.25, n.2, p.139-153.

ZEITHAML, Valarie A. Consumer Perceptions of Price, Quality, and Value: AMeans-End Model and Synthesis of Evidence. Journal of Marketing. V.52, n.3, p. 2-21, July, 1988.

Informações bibliográficas:

Conforme a NBR 6023:2002 da Associação Brasileira de Normas Técnicas (ABNT), este texto científico publicado em periódico eletrônico deve ser citado da seguinte forma:

NASR, Maria Aparecida; SANTOS, Zilda Maria Contesini dos. A influência da marca nos postos de abastecimento de combustíveis. Cadernos UniFOA, Volta Redonda, ano 2, nº . 5, dez. 2007. Disponível em: $<$ http://www.unifoa.edu.br/pesquisa/caderno/edicao/05/34.pdf $>$ 